Review Article

\title{
Sphingosine-1-Phosphate and Its Receptors: A Mutual Link between Blood Coagulation and Inflammation
}

\author{
Shailaja Mahajan-Thakur, ${ }^{1}$ Andreas Böhm, ${ }^{1}$ Gabriele Jedlitschky, \\ Karsten Schrör, ${ }^{2}$ and Bernhard H. Rauch ${ }^{1}$ \\ ${ }^{1}$ Institut für Pharmakologie, Universitätsmedizin Greifswald, Felix-Hausdorf Strasse 3, 17487 Greifswald, Germany \\ ${ }^{2}$ Institut für Pharmakologie und Klinische Pharmakologie, Universitätsklinikum Düsseldorf, Universitätsstrasse 1, \\ 40225 Düsseldorf, Germany
}

Correspondence should be addressed to Bernhard H. Rauch; bernhard.rauch@uni-greifswald.de

Received 14 July 2015; Revised 26 September 2015; Accepted 30 September 2015

Academic Editor: Ashley Snider

Copyright (C) 2015 Shailaja Mahajan-Thakur et al. This is an open access article distributed under the Creative Commons Attribution License, which permits unrestricted use, distribution, and reproduction in any medium, provided the original work is properly cited.

\begin{abstract}
Sphingosine-1-phosphate (S1P) is a versatile lipid signaling molecule and key regulator in vascular inflammation. S1P is secreted by platelets, monocytes, and vascular endothelial and smooth muscle cells. It binds specifically to a family of G-protein-coupled receptors, S1P receptors 1 to 5, resulting in downstream signaling and numerous cellular effects. S1P modulates cell proliferation and migration, and mediates proinflammatory responses and apoptosis. In the vascular barrier, S1P regulates permeability and endothelial reactions and recruitment of monocytes and may modulate atherosclerosis. Only recently has S1P emerged as a critical mediator which directly links the coagulation factor system to vascular inflammation. The multifunctional proteases thrombin and FXa regulate local S1P availability and interact with S1P signaling at multiple levels in various vascular cell types. Differential expression patterns and intracellular signaling pathways of each receptor enable S1P to exert its widespread functions. Although a vast amount of information is available about the functions of S1P and its receptors in the regulation of physiological and pathophysiological conditions, S1P-mediated mechanisms in the vasculature remain to be elucidated. This review summarizes recent findings regarding the role of S1P and its receptors in vascular wall and blood cells, which link the coagulation system to inflammatory responses in the vasculature.
\end{abstract}

\section{Introduction}

Sphingosine-1-phosphate (S1P), a highly active lipid mediator, exhibits a broad range of cellular activities including proliferation, survival, adhesion, and migration $[1,2]$. S1P is critical for mammalian cardiac development and for maturation of the systemic circulatory system [3]. These biological actions are carried out by predominantly intracellularly produced S1P via sphingosine kinase (SphK), of which two isoforms SphK1 and SphK2 exist $[4,5]$. Moreover, S1P has emerged as an intracellular second messenger involved in regulation of cell proliferation and in mobilization of internal calcium stores by a protein kinase $\mathrm{C}$ independent pathway [6]. Further reports suggest that S1P found within the extracellular space is not merely derived from intracellular generation but biosynthetic enzymes of the S1P metabolism appear to subsist in the extracellular space [7]. Indeed, the majority of studies have focused on the functions of extracellular S1P. This "outside the cell" S1P acts in an autocrine or paracrine manner as an agonist for a unique family of G-protein-coupled receptors which to date comprises the five S1P receptors (S1PRs) S1PR1-S1PR5 [8, 9]. Extracellular S1P regulates proliferation and migration of vascular endothelial cells (ECs) [10] and smooth muscle cells (VSMCs) [11] and critically determines lymphocyte egress and angiogenesis [12]. Both S1P and S1PRs regulate vascular tone either by directly modulating the smooth muscle layer or by stimulating ECs to release bioactive molecules which regulate VSMCs responses in a paracrine manner [13].

The levels of S1P in plasma and tissues are tightly regulated by the balance between its synthesis by sphingosine 
kinases and degradation $[2,14]$. The role of S1P and the processes involved in its biosynthesis, that is, regulation of the metabolizing enzymes, for controlling vascular integrity has been studied thoroughly in vitro and in vivo [15]. Vascular proliferative disorders such as atherosclerosis and persistent proinflammatory challenges of the vessel wall [16] are characterized by the activation of the coagulation cascade and platelet activation, both processes which elevate local S1P concentrations [17]. This may play an important role in directing immune cells to sites of local injury and directly links the coagulation system to S1P-mediated inflammatory responses in vivo. After vascular injury, the coagulation cascade is initiated by activating the clotting factors X (FXa) and ultimately thrombin, which are both key regulators of subsequent tissue repair and remodeling $[18,19]$. FXamediated thrombin generation initiates and is itself amplified by subsequent platelet activation, finally leading to cleavage of fibrinogen and eventually the formation of the mural thrombus [20, 21]. In addition to their physiological function in hemostasis, the clotting proteases thrombin and FXa are also accountable for clinically relevant pathological responses such as postphlebitic inflammatory and tissue repair reactions $[16,22]$. The biological effects of FXa and thrombin are mediated via a family of G-protein-coupled receptors, protease-activated receptors $1,2,3$, and 4 (PAR-1-PAR-4) $[23,24]$. Thrombin initiates signaling through PAR-1, PAR3 , and PAR-4, while FXa acts via PAR-1 and PAR-2. Previous reports, including studies from our group, have reported that PARs stimulate VSMCs proliferation and migration, modify the composition of the extracellular matrix of blood vessels, and mediate proinflammatory responses in the vessel wall [25-28]. Because proliferation and migration of VSMCs are considered key events in the development of atherosclerosis and vascular remodeling, these cellular effects of thrombin and FXa may directly contribute to the pathogenesis of vascular diseases such as progression of atherosclerosis and restenosis after vascular injury. In addition, recent studies highlight numerous interactions between blood coagulation and the S1P signaling system [17, 29].

This review discusses the recent findings concerning the role of S1P and its receptors in vascular and blood cells which are interlinked with the coagulation system. Particularly, hemostasis-related mechanisms which increase local S1P availability and the regulation of PAR receptor expression by S1P are highlighted. Elucidating the complex interactions between blood coagulation and the S1P signaling network further may bear the potential to discover and develop novel targets for the therapy of inflammation-prone vascular diseases.

\section{Biosynthesis, Degradation, and Functions of S1P in the Vascular System}

S1P biosynthesis is tightly interlinked with the metabolism of ceramide. Ceramide is formed either de novo from serine, palmitoyl CoA, and fatty acid or from breakdown of membrane-resident sphingomyelin [30, 31]. Ceramide is further converted to sphingosine by enzymatic action of ceramidase. Finally, the bioactive lysophospholipid S1P is produced by phosphorylation of sphingosine. This reaction is catalyzed by the two sphingosine kinase isoenzymes SphK1 and SphK2. Maintaining a balance between S1P generation and degradation is critical for regulation of cell growth and plays a key role in pathological processes such as carcinogenesis [32]. S1P degradation is achieved via reversible dephosphorylation by two S1P-specific phosphatases (SPP1 and SPP2) or irreversible hydrolysis by S1P lyase. S1P exerts actions either by binding to its intracellular targets or through its specific receptor in autocrine, paracrine, and/or endocrine manner [31].

S1P is secreted, stored, and exported by the cells of the vessel wall, VSMCs, and ECs, respectively. Recent observations highlight the critical role of the putative S1P transporter spinster homolog 2 (Spns2) in endothelial S1P release and in lymphocyte trafficking $[33,34]$. In other cell types, that is, breast cancer and mast cell, the ABC (ATP-binding cassette) transporter family members $\mathrm{ABCC} 1$ and $\mathrm{ABCG} 2$, known regulators of inflammatory processes, facilitate export of S1P across the cell membrane $[35,36]$. S1P regulates a diverse range of cellular processes that are important in immunity, inflammation, and inflammatory disorders $[37,38]$. Once secreted, most of the S1P binds to albumin or serum lipoproteins [39]. Whether this carrier-bound serum S1P or rather locally produced S1P is important for the diverse cellular functions is a matter of current debate [40]. The metabolism and distinct vascular functions of S1P are highlighted in Figure 1.

\section{Interactions of S1P Receptors and Thrombin Receptors Affect Endothelial Function}

Endothelial cells synthesize and secrete large amounts of S1P and contribute substantially to generating the high S1P level present in the blood [40, 41]. Of the five S1PRs, endothelial cells express S1PR1, S1PR2, and S1PR3 [29]. S1P modulates diverse endothelial activities including proliferation [42], survival [43], migration [44], and regulation of proinflammatory responses [45] and controls the endothelial barrier function [46-49]. S1PR1 is highly expressed in endothelial cells [50] and regulates cytoskeletal structure, migration, and vessel maturation $[51,52]$. In S1PR1 receptor deficient embryos, blood vessels were incompletely covered by VSMCs, indicating that S1PR1 also regulates vascular maturation [53]. Thus, S1PR1 appears to mediate predominantly physiological functions while particularly S1PR2 regulates inflammatory endothelial responses and is upregulated during inflammatory conditions such as atherosclerosis [45, 54]. These assumptions are in agreement with recent observations of varying S1P concentrations resulting in differential receptor activation [55] and the differential regulation of S1PR1 and S1PR2 expression during conditions of hyperglycemiainduced endothelial cell dysfunction [56].

A key regulator of endothelial function is the coagulation system with factors such as thrombin known to affect its permeability [57] as well as endothelial inflammation [58]. Thrombin causes induction of endothelial cell contraction 


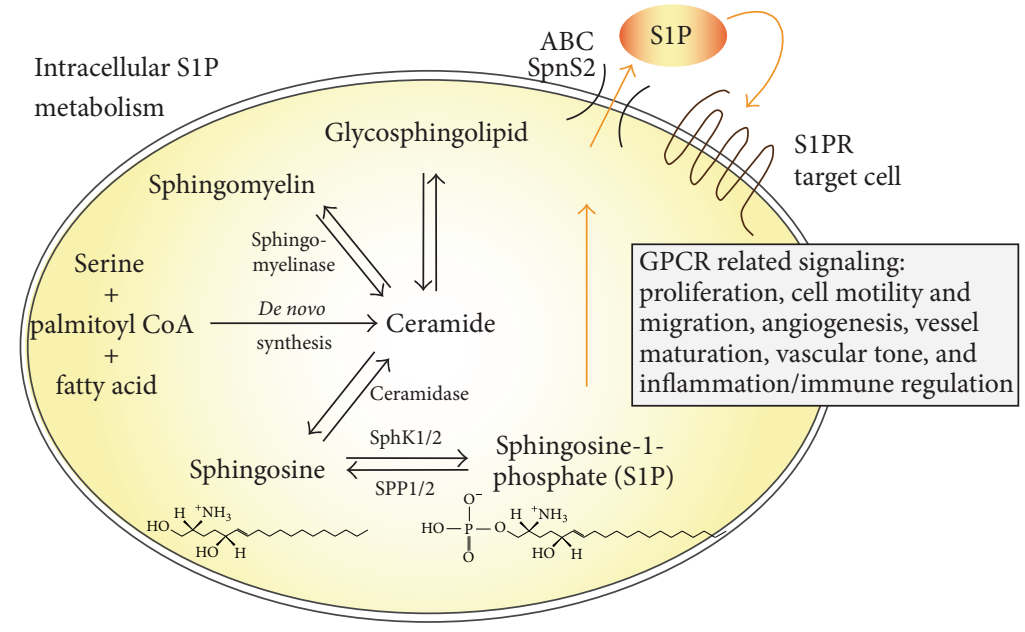

FIgure 1: Synthesis of S1P and functions in the vascular system. De novo ceramide synthesis in general originates from condensation of serine, palmitoyl CoA, and fatty acid, a multistep enzyme catalysed process. Ceramide can be converted reversibly into sphingomyelin by sphingomyelinase or to glycosphingolipids. It is further metabolised by ceramidase to sphingosine, which can then be phosphorylated into S1P by sphingosine kinase isoforms 1 and 2 (SphK1/2). This phosphorylation can be reverted by the S1P phosphatases SPP1 and SPP2 or irreversible degradation by S1P lyase can occur. S1P may act intracellularly or is exported out of the cell via ABC transporters or Spns2, dependent on the cell type, and may bind to one of its receptors (S1PR1-S1PR5) to initiate G-protein mediated signaling. S1P modulates key processes of vascular pathogenesis which involve but are not restricted to modulation of cell proliferation and migration and regulation of vascular tone and immune functions.

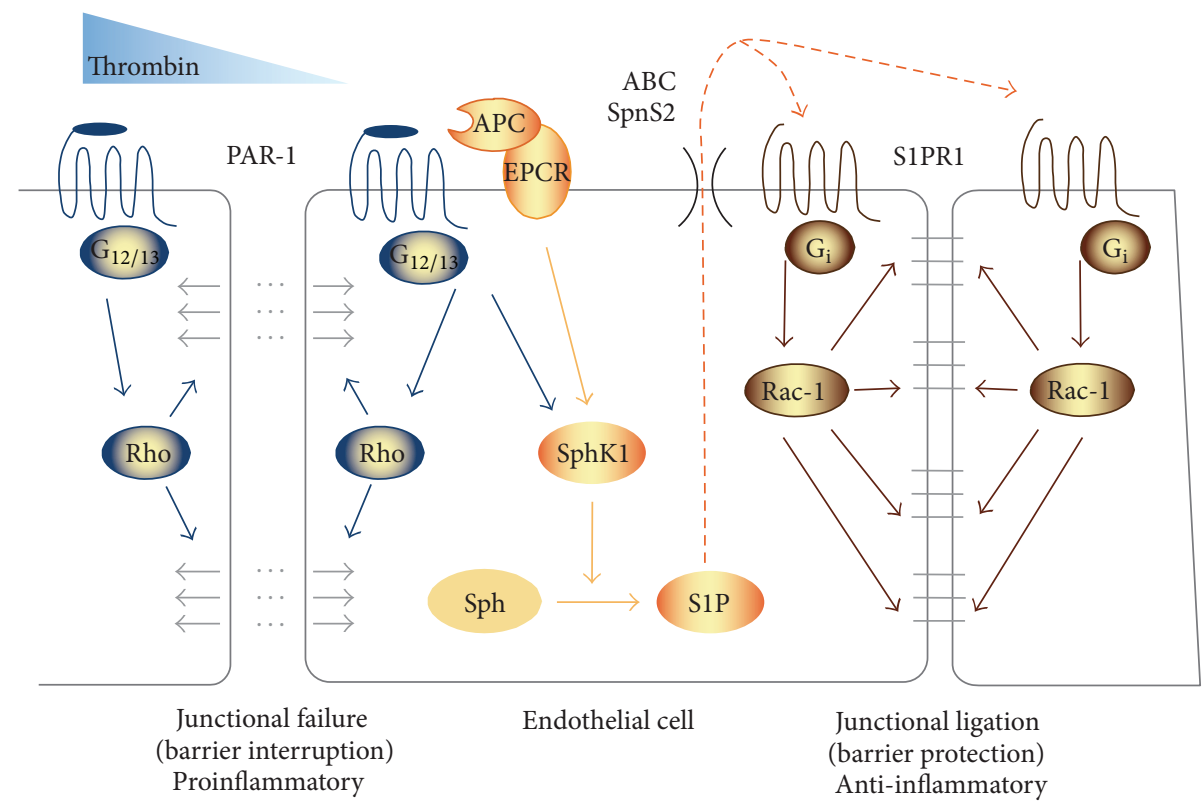

FIgURE 2: Thrombin effects in endothelial cells involve S1P signaling. Activation of the classical thrombin receptor PAR-1 interrupts endothelial barrier integrity by induction of endothelial contraction through stimulation of $\mathrm{G}_{12 / 13}$ subunit and Rho signalling pathway (left). Conversely, thrombin also induces expression of SphK1 and increases S1P generation. This involves PAR-1-induced signaling via activated protein C (APC) and the endothelial protein C receptor (EPCR). S1P in turn transactivates S1PR1 leading to $\mathrm{G}_{\mathrm{i}}$-dependent activation of the Rac-1 signaling pathway. This effect improves endothelial integrity to counteract and limit thrombin-induced endothelial damage and vascular leakage (right).

and disruption of endothelial barrier integrity via the PAR-1 receptor [57]. This involves signaling through the endothelial protein C receptor and includes cross talk with the S1PR system [59]. S1P/S1PR signaling can counteract this detrimental effect of thrombin and appears to protect from vascular leakage and tissue damage such as edema formation [60]. Thus, thrombin may enhance endothelial S1P generation and signaling within the endothelium to limit its own actions of inducing vascular leakage via mutual PAR-1 mediated S1P/S1PR1 actions (Figure 2). 
TABLE 1: Mechanistic studies which directly link S1P and its receptors to the thrombin or FXa receptors PAR-1 to PAR-4, their (patho)physiological actions, and associated signaling pathways.

\begin{tabular}{llll}
\hline Receptor(s)/stimuli & G-protein binding & Signaling pathway & Physiological action(s) \\
\hline $\begin{array}{l}\text { S1P/thrombin } \\
\text { S1P/thrombin }\end{array}$ & Not described & NF- $\kappa$ B, EGR-1/ERK1/2 & $\begin{array}{l}\text { Enhanced tissue factor expression in } \\
\text { endothelial cells }\end{array}$ \\
\hline $\begin{array}{l}\text { S1PR3/PAR-1 } \\
\text { (via SphK1) }\end{array}$ & GIT1 and GIT2 & $\begin{array}{l}\text { Focal adhesion kinase } \\
\text { (FAK)/Src }\end{array}$ & Regulation of endothelial barrier function \\
\hline $\begin{array}{l}\text { S1PR1 and S1PR3/PAR-1 } \\
\text { [51P/PAR-1 } \\
\text { (via SphK1) }\end{array}$ & $\mathrm{G}_{12 / 13}$ & $\mathrm{IL}-1 \mathrm{~B}$ & $\begin{array}{l}\text { Induces tissue factor production, } \\
\text { inflammation, and coagulation }\end{array}$ \\
\hline $\begin{array}{l}\text { SphK1/FXa via } \\
\text { PAR-1 and PAR-2 }\end{array}$ & $\mathrm{G}_{12 / 13}$ & Rac-1/Rho & Inflammatory responses \\
\hline $\begin{array}{l}\text { S1P/FXa } \\
\text { S1PR3/PAR-4 }\end{array}$ & $\mathrm{Gq}$ & NF- $\kappa \mathrm{B}$ & Regulation of endothelial function \\
\hline
\end{tabular}

In certain systemic diseases such as sepsis, signaling through PAR-1 exerts multiple and partly opposing functions. This has been attributed to either promoting dendritic cell-dependent coagulation and inflammation or reducing sepsis lethality due to protein $\mathrm{C}$ activation and involves regulation of the balance between differential vascular S1PR (S1PR1/S1PR3) signaling pathways [59]. Thus, not only PAR signaling but also S1P actions in endothelial cells appear to involve opposing mechanisms and cellular effects. On the one hand, S1P enhances barrier integrity to counteract thrombin-mediated disturbance of permeability to restore vascular homeostasis after injury; on the other hand, it synergizes with thrombin in upregulating the expression of TF in endothelial cells [61]. Thereby, S1P may enhance generation of thrombin under proinflammatory conditions such as atherosclerosis. In this context, a recent study from Campos et al. is of interest, which showed that the functional S1P receptor antagonist fingolimod [62] reduces infarct size and enhances blood-brain barrier integrity in rodent models of stroke [63]. To determine whether this observation, besides an effect on barrier function, involves direct thrombotic or antithrombotic mechanisms of S1P signaling requires further investigations. The mechanistic studies which directly link S1P and its receptors to the thrombin or FXa receptors, their (patho)physiological actions, and associated signaling pathways are summarized in Table 1.

\section{Role of Coagulation Factor-S1P Interactions in the Vessel Wall}

Proliferation and migration of vascular VSMCs are fundamental features in physiological processes such as maturation of blood vessel [64] as well as during vascular lesion formation [65]. Numerous growth factors and inflammatory molecules like cytokines regulate VSMCs proliferation and migration. Early studies also suggested a function of S1P for DNA synthesis and migration in VSMCs [66]. Since then, S1P has rapidly been gaining attention as a key regulator of VSMCs functions and vascular development as well as a critical factor for vascular damage. Like endothelial cells, VSMCs obtained from different vascular beds express S1PR1, S1PR2, and S1PR3 receptors [67-71]. Kluk and Hla reported that S1P via activation of S1PR1 significantly stimulates both proliferative and migratory responses for VSMCs [70]. This is in agreement with the observation that S1P induces VSMCs migration through a G $\alpha$ i-linked, Ras- and PI3-K-coupled, ERK1/2-dependent process [71]. A further role of S1PR2 receptor in vascular physiology and pathology has been established through regulation of intracellular signaling pathways, such as Rho GTPase, the phosphatase PTEN, and VEcadherin pathways [72]. Nodai et al. found high mRNA levels of the receptors S1PR2 and S1PR3 in rat VSMCs [73]. They suggest that predominantly S1PR3 stimulates expression of COX-2 through mechanisms involving calcium-dependent PKC and Src-family tyrosine kinase [73].

The relevance of S1P in the regulation of vascular permeability, lymphocyte trafficking, and vascular development is well documented in vivo [41]. S1PR1 deficiency resulted in impaired vascular maturation [74] whereas SphK1 and SphK2 null mice have shown disturbed angiogenesis resulting in embryonic lethality [75]. Furthermore, Kono et al. reported that S1PR1, S1PR2, and S1RP3 function coordinately during embryonic angiogenesis [76]. Taken together, these studies suggest S1P governs physiological vascular homeostasis and is also an important mediator during pathophysiological conditions such as inflammation.

The coagulation system has been well recognized as a key regulator of inflammation. An interaction between thrombin-induced PAR-1 signaling and the S1P system via enhanced expression of SphK1 and elevated S1P synthesis has first been observed in epithelial and in endothelial cells [77]. In addition, the S1P system has been suggested as a downstream component of thrombin signaling also in other cell types. Work from Niessen et al. revealed a critical role of cross talk between PAR-1 and the S1PR3 receptor in dendritic cells in the amplification of inflammation during sepsis [78]. Further studies indicate direct involvement of thrombin in regulating key processes of cellular proinflammatory responses 


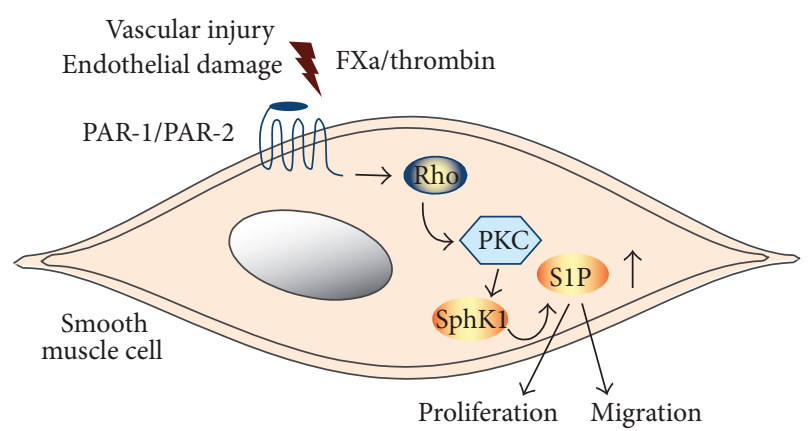

FIGURE 3: The coagulation proteases thrombin and activated factor $\mathrm{X}$ (FXa) enhance S1P synthesis and release from vascular smooth muscle cells (VSCMs). During vascular injury, local generation of thrombin and FXa enhances the synthesis and the release of S1P via activation of PAR-1 and PAR-2, respectively. This signaling pathway involves activation of the small GTPase Rho and PKC signaling leading to transcriptional upregulation of SphK-1. The resulting S1P activities regulate proliferation and migration of VSMCs.

in VSMCs. This involves activation of classical inflammatory transcription factors such as NF- $\kappa$ B [79], but also immune regulators that have more recently become of interest, that is, the forkhead-box-O transcription factor family [80].

In addition to thrombin, FXa can independently activate PAR-1 and PAR-2. Recent work from our laboratory has shown that FXa regulates transcription of SphK1 and elevates S1P biosynthesis in human vascular smooth muscle cells (Figure 3) [81]. This stimulatory effect, observed in cultured cells, was seen at FXa concentrations ( 3 to $30 \mathrm{nM}$ ) which have been shown to occur during thrombus formation ex vivo [26]. Expression of SphK1 by FXa was attenuated by inhibitors of the Rho-associated kinase and of classical PKC isoforms. In addition, FXa caused activation of the small GTPase RhoA in human smooth muscle cells. This is particularly interesting, because small GTPases are known to play key roles in mediating signaling responses of the S1P receptor [82], suggesting a mutual interaction of S1P receptor-initiated signaling and regulation of S1P synthesis. Interestingly, FX/FXa appears to be already present within human carotid artery plaques (plaque material is well known to be highly thrombotic) and colocalizes with SphK1 expression [81]. The presence of active coagulation factors in atherosclerotic tissue has also been shown by others [83]. This observation suggests a close relation between coagulation factor signaling and progression of the atherothrombotic disease. Whether possible antiproliferative or antiatherogenic actions of the novel oral coagulation inhibitors involve affecting SphK1 expression and possibly modification of S1P-mediated signaling in patients requires further investigations.

\section{Release Mechanisms of S1P from Activated Platelets}

The biological effects of S1P released from activated platelets in the vasculature include inhibition of platelet aggregation [84], angiogenesis, vascular development, and thrombosis-related vascular diseases such as the acute coronary syndrome $[47,85,86]$. Platelets were originally suggested to be the prime source of plasma S1P, because they exhibit high SphK activity. In human platelets, SphK2 is the predominant isoform [87]. Surprisingly, however, although platelets do express S1P receptors [88] during in vitro platelet function testing such as light transmission aggregometry, S1P does not appear to function as a potent direct platelet agonist [89].

Due to lack of S1P lyase activity in platelets [90], S1P abundantly accumulates intracellularly. However, S1P plasma levels in thrombocytopenic mice were found to remain largely unchanged [91], suggesting that resting platelets may not substantially contribute to circulating S1P concentrations in plasma. Platelets release huge amounts of S1P during blood clotting or upon direct activation with agonists of PKC signaling like thrombin $[92,93]$. Work from our laboratory suggests a critical role of thromboxane in regulating the release of S1P from human platelets [89]. Secretion of S1P was induced after activation of platelets with potent agonists such as thrombin or selective PAR-activating peptides (PARAPs) or with a high concentration of collagen. This effect was largely prevented after inhibition of thromboxane formation by classical inhibitors of cyclooxygenase-1 (COX-1), such as aspirin, diclofenac, or ibuprofen (Figure 4 and [89]). Thus, one pathway mediating release of platelet-derived S1P after platelet activation depends on COX-1-derived thromboxane.

Since S1P represents an amphiphilic anion, its translocation across the plasma membrane supposedly does require active transport proteins. As mentioned above, several studies in various cell types point to the involvement of a transporter of the ABC family $[94,95]$. However, the biological functions of these proteins are by far not completely understood. In activated platelets, S1P secretion was affected by several compounds that are known to inhibit members of the multidrug resistance protein (MRP/ABCC) subfamily of $A B C$ transporters [89]. A variety of transporters including MRPs are expressed in platelets that exert important functions for translocation and storage of signaling molecules [96-98]. Further studies are required to identify the proteins involved in the export of S1P out of the cells. The elucidation of the mechanisms of S1P release would also provide the opportunity of pharmacological modulation of the transport process.

\section{Interactions of the S1P-PAR System for Inflammatory Monocyte Responses}

During vascular inflammation, monocytes secrete several proinflammatory cytokines and adhesion molecules, a response mechanism which facilitates recruitment and adherence to the inflamed and activated endothelium [99]. Thrombin is one of the key factors controlling the migratory and secretory behavior of monocytes [100]. Human peripheral blood monocytes predominantly express PAR1 and PAR-3 [101]. Interestingly, during differentiation into macrophages, that is, by colony-stimulating factors, the expression levels of PAR-1, PAR-2, and PAR-3 are highly elevated indicating dynamic adaptation mechanisms 


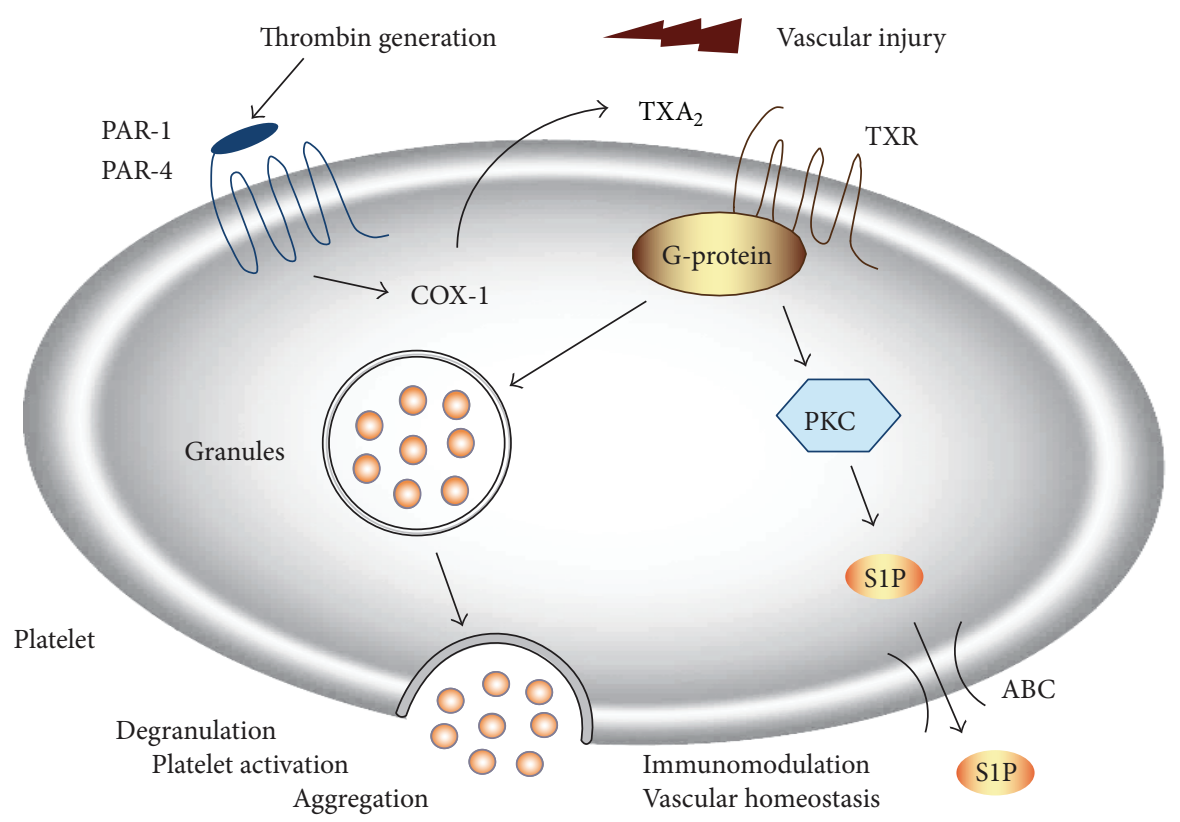

FIgURE 4: Thrombin-stimulated S1P secretion in human platelets. Thrombin triggers COX-1-mediated synthesis of thromboxane $\mathrm{A}_{2}$ (TXA $\mathrm{T}_{2}$ ) via activation of platelet PAR-1. Consecutive TX release and activation of thromboxane $\mathrm{A}_{2}$ receptor (TXR) enhances platelet degranulation and aggregation. In parallel, $\mathrm{TXA}_{2}-\mathrm{TXR}$ signaling stimulates platelet S1P secretion. This pathway involves activation protein kinase $\mathrm{C}$ (PKC) and appears to be mediated by an ATP-dependent transport mechanism (ABC, ATP-binding cassette transporter). In a paracrine manner, platelet-derived S1P may modulate endothelial and immune cell responses at sites of injury.

of the system [101]. A recent report indicates that monocytes from patients with antiphospholipid syndrome expressed PAR-1 to PAR-3 but not PAR-4 [102]. Other authors have described a role for PAR-4 in the release of inflammatory markers from monocytes, such as IL-6 [103]. Thus, different PARs may be differentially regulated in response to various stimuli during vascular pathogenesis.

$\mathrm{S} 1 \mathrm{P}$ is a recently recognized novel regulator also of monocyte functions [104, 105]. Human monocytes express all five S1PRs at the mRNA and protein levels [106], possibly mediating the regulation of monocyte apoptosis and chemotaxis [107]. In leukocytes, S1P contributes to P-selectin-dependent rolling through endothelial S1PR3 [108]. In dendritic and endothelial cells, involvement of S1P in the signaling pathways of the prototypic thrombin receptor PAR-1 has been suggested [80]. However, little information is to date available about a possible cross talk between S1P and PARs in monocytes. Recent data from our laboratory provide evidence that (i) S1P directly enhances expression of the thrombin receptors PAR-1 and PAR- 4 in human monocytes and that (ii) this results in enhanced PAR-4-mediated chemotaxis and elevated generation of COX-2 in response to thrombin [109].

S1P induced PAR-1 and PAR-4 mRNA and total protein expression in human monocytes and U937 cells in a concentration- and time-dependent manner, respectively. However, only PAR-4 cell-surface expression was increased significantly by S1P, whereas cell-surface PAR-1 remained unaffected. This response was associated with activation of the Akt, ERK1/2, and p38 pathway and induction of COX-2 but not COX-1. PAR-4-mediated induction of COX2 was prevented by pharmacological inhibition of the PI3 kinase pathway and incubation of human monocytes with S1P resulted in an enhanced PAR-4-dependent chemotaxis response to thrombin. Thus, S1P enhances monocyte responses to thrombin via upregulation of PAR-4 protein and cell-surface expression, which promotes migration and COX2 abundance. These studies establish a direct link between S1P receptor activation and regulation of thrombin receptor expression in human monocyte and the subsequent cellular responses to thrombin. This mechanism may facilitate monocyte recruitment to sites of vessel injury and inflammation (Figure 5).

\section{Summary and Perspective}

Taken together, complex (patho)physiological interactions between blood coagulation factors and S1P and their respective signaling receptors are being increasingly recognized (see Table 1). This involves regulation of endothelial, smooth muscle, and immune cell functions. Of particular interest for the clinic is the use of new selective modulators of the S1P-S1PR signaling system such as fingolimod as therapeutic agents. In the cardiovascular system, the role of S1P as therapeutic target or as a potential biomarker in cardiovascular diseases is still unclear. For example, the role of S1P levels and release, that is, from thrombin-activated platelets during myocardial infarction, is not finally defined to date. Recent studies indicate that S1P levels substantially vary during cardiovascular disease entities [110, 111]. An important future issue is the definition of circulating S1P levels in defined study populations as well as in clinical cohorts such as patients 


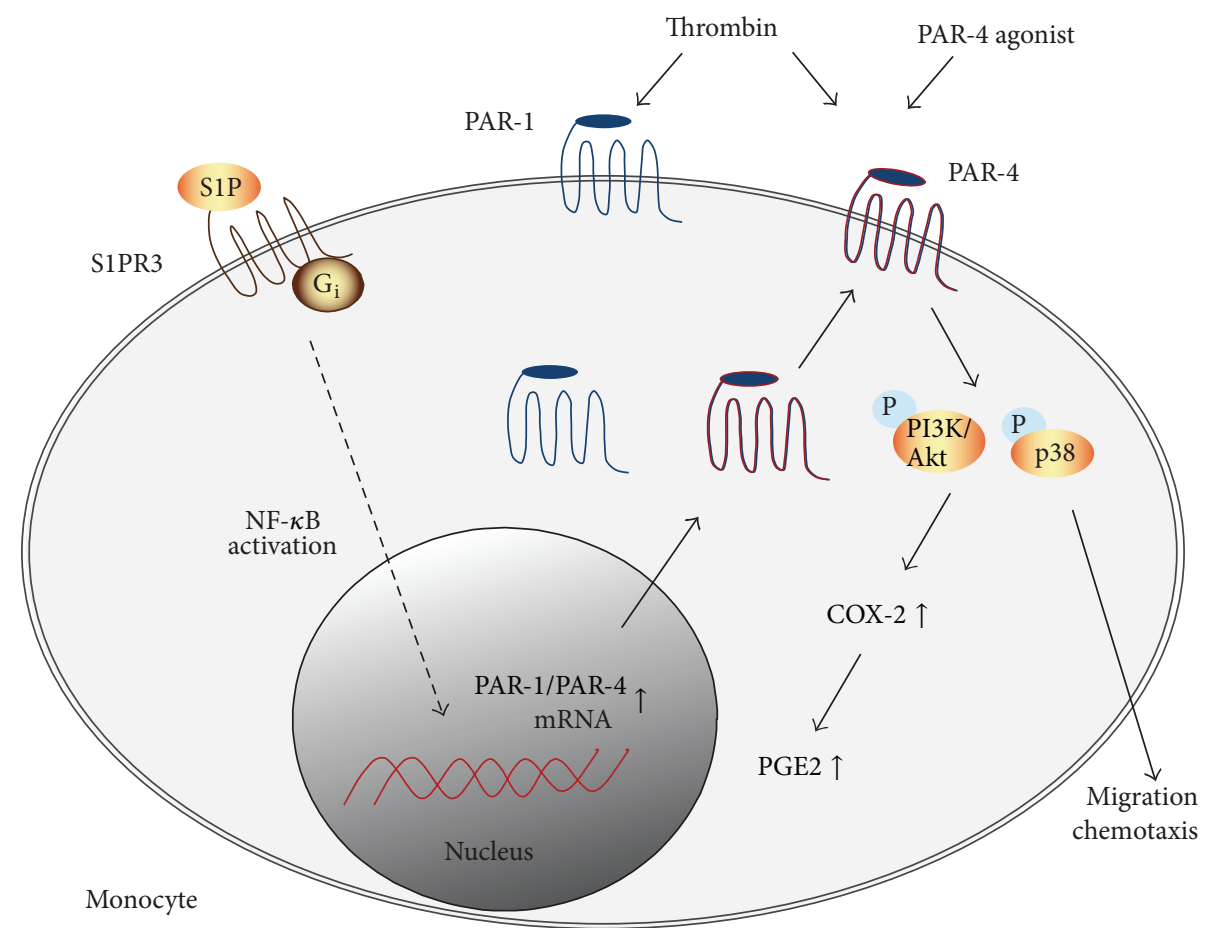

FIGURE 5: Interactions of S1PRs and PARs in monocyte function. In human monocytes, S1P significantly enhances expression of the thrombin receptors PAR-1 and PAR-4 at the mRNA and protein level. Elevation of PAR-1/PAR-4 abundance appears to be mediated via activation of S1PR3 and results in increased migration of the monocyte toward thrombin. These responses are associated with PI3K/Akt-mediated expression of COX-2. At sites of vascular injury, increased levels of S1P, for example, released from aggregating platelets, may enhance the inflammatory response of local monocytes, thereby modulating tissue-targeted events such as thrombosis and vessel injury.

with acute coronary syndrome. The clinical relevance and therapeutic potential of altering S1P levels or receptor activity in atherothrombosis associated diseases is to date unclear and warrants future studies.

\section{Abbreviations}

$\mathrm{ABC}$ :

Adenosine triphosphate-binding cassette transporter

APC:

COX-1:

Activated protein $\mathrm{C}$

EGR-1:

Cyclooxygenase-1

EPCR:

FAK:

FXa:

$\mathrm{NF}-\kappa \mathrm{B}$ :

Early growth response protein 1

Endothelial protein $\mathrm{C}$ receptor

Focal adhesion kinase

Activated coagulation factor $\mathrm{X}$

Nuclear factor- $\kappa \mathrm{B}$

PAR-1/PAR-2/PAR-4: Protease-activated receptor 1/2/4

p38 MAPK:

PI3K:

PAR-4AP:

PGE2:

PKC:

Rac-1:

Rho:

S1P: p38 mitogen-activated protein

kinases

Phosphatidylinositol-3-kinases

PAR-4 activating peptide

Prostaglandin E2

Protein kinase $\mathrm{C}$

Ras-related C3 botulinum toxin substrate 1

Ras-homologue GTPase family

member

Sphingosine-1-phosphate
S1P1-S1P3: S1P receptors 1 to 3

Sph: Sphingosine

SphK-1: $\quad$ Sphingosine kinase-1

Spns2: $\quad$ Spinster homolog 2

$\mathrm{TXA}_{2}$ : Thromboxane $\mathrm{A}_{2}$

W146: S1PR1 antagonist

CAY: $\quad$ S1P3 antagonist

LY: $\quad$ An inhibitor of PI3K upstream of Akt

SB: $\quad$ p38 MAPK inhibitor.

\section{Conflict of Interests}

The authors declare that there is no conflict of interests regarding the publication of this paper.

\section{Acknowledgments}

The authors are grateful to Ivette Fronczek for expert secretarial assistance. The work of the authors was supported by grants of the Deutsche Forschungsgemeinschaft (RA-1417/1-2 and Je-234/4-1).

\section{References}

[1] H. Rosen and E. J. Goetzl, "Sphingosine 1-phosphate and its receptors: an autocrine and paracrine network," Nature Reviews Immunology, vol. 5, no. 7, pp. 560-570, 2005. 
[2] K. Takabe, S. W. Paugh, S. Milstien, and S. Spiegel, "Insideout' signaling of sphingosine-1-phosphate: therapeutic targets," Pharmacological Reviews, vol. 60, no. 2, pp. 181-195, 2008.

[3] H. Fyrst and J. D. Saba, "An update on sphingosine-1-phosphate and other sphingolipid mediators," Nature Chemical Biology, vol. 6, no. 7, pp. 489-497, 2010.

[4] A. J. Melendez, E. Carlos-Dias, M. Gosink, J. M. Allen, and L. Takacs, "Human sphingosine kinase: molecular cloning, functional characterization and tissue distribution," Gene, vol. 251, no. 1, pp. 19-26, 2000.

[5] H. Liu, M. Sugiura, V. E. Nava et al., "Molecular cloning and functional characterization of a novel mammalian sphingosine kinase type 2 isoform," The Journal of Biological Chemistry, vol. 275, no. 26, pp. 19513-19520, 2000.

[6] M. Mattie, G. Brooker, and S. Spiegel, "Sphingosine-1phosphate, a putative second messenger, mobilizes calcium from internal stores via an inositol trisphosphate-independent pathway," The Journal of Biological Chemistry, vol. 269, no. 5, pp. 3181-3188, 1994.

[7] N. Ancellin, C. Colmont, J. Su et al., "Extracellular export of sphingosine kinase-1 enzyme. Sphingosine 1-phosphate generation and the induction of angiogenic vascular maturation," Journal of Biological Chemistry, vol. 277, no. 8, pp. 6667-6675, 2002.

[8] V. A. Blaho and T. Hla, "An update on the biology of sphingosine 1-phosphate receptors," The Journal of Lipid Research, vol. 55, pp. 1596-1608, 2014.

[9] Y. Kihara, M. Maceyka, S. Spiegel, and J. Chun, "Lysophospholipid receptor nomenclature review: IUPHAR Review 8," British Journal of Pharmacology, vol. 171, no. 15, pp. 3575-3594, 2014.

[10] T. Kimura, T. Watanabe, K. Sato et al., "Sphingosine 1-phosphate stimulates proliferation and migration of human endothelial cells possibly through the lipid receptors, Edg-1 and Edg-3," Biochemical Journal, vol. 348, part 1, pp. 71-76, 2000.

[11] S. Inoue, T. Nakazawa, A. Cho et al., "Regulation of arterial lesions in mice depends on differential smooth muscle cell migration: a role for sphingosine-1-phosphate receptors," Journal of Vascular Surgery, vol. 46, no. 4, pp. 756-763, 2007.

[12] J. G. Cyster and S. R. Schwab, "Sphingosine-1-phosphate and lymphocyte egress from lymphoid organs," Annual Review of Immunology, vol. 30, pp. 69-94, 2012.

[13] J. Igarashi and T. Michel, "Sphingosine-1-phosphate and modulation of vascular tone," Cardiovascular Research, vol. 82, no. 2, pp. 212-220, 2009.

[14] A. V. Thuy, C.-M. Reimann, N. Y. A. Hemdan, and M. H. Gräler, "Sphingosine 1-phosphate in blood: function, metabolism, and fate," Cellular Physiology and Biochemistry, vol. 34, no. 1, pp. 158171, 2014.

[15] E. Camerer, J. B. Regard, I. Cornelissen et al., "Sphingosine1-phosphate in the plasma compartment regulates basal and inflammation-induced vascular leak in mice," Journal of Clinical Investigation, vol. 119, no. 7, pp. 1871-1879, 2009.

[16] J. Kalz, H. ten Cate, and H. M. H. Spronk, “Thrombin generation and atherosclerosis," Journal of Thrombosis and Thrombolysis, vol. 37, no. 1, pp. 45-55, 2014.

[17] B. H. Rauch, "Sphingosine 1-phosphate as a link between blood coagulation and inflammation," Cellular Physiology and Biochemistry, vol. 34, no. 1, pp. 185-196, 2014.

[18] A. T. Nurden, "Platelets, inflammation and tissue regeneration," Thrombosis and Haemostasis, vol. 105, supplement 1, pp. 13-33, 2011.
[19] M. Levi, T. van der Poll, and M. Schultz, "Infection and inflammation as risk factors for thrombosis and atherosclerosis," Seminars in Thrombosis and Hemostasis, vol. 38, no. 5, pp. 506514, 2012.

[20] M. A. Krupiczojc, C. J. Scotton, and R. C. Chambers, "Coagulation signalling following tissue injury: focus on the role of factor Xa," The International Journal of Biochemistry \& Cell Biology, vol. 40, no. 6-7, pp. 1228-1237, 2008.

[21] A. P. Owens III and N. MacKman, "Role of tissue factor in atherothrombosis," Current Atherosclerosis Reports, vol. 14, no. 5, pp. 394-401, 2012.

[22] K. Borensztajn, M. P. Peppelenbosch, and C. A. Spek, "Factor $\mathrm{Xa}$ : at the crossroads between coagulation and signaling in physiology and disease," Trends in Molecular Medicine, vol. 14, no. 10, pp. 429-440, 2008.

[23] K. Schrör, E. Bretschneider, K. Fischer et al., "Thrombin receptors in vascular smooth muscle cells-function and regulation by vasodilatory prostaglandins," Thrombosis and Haemostasis, vol. 103, no. 5, pp. 884-890, 2010.

[24] L. Ma and A. Dorling, "The roles of thrombin and protease-activated receptors in inflammation," Seminars in Immunopathology, vol. 34, no. 1, pp. 63-72, 2012.

[25] S. R. Coughlin, "Protease-activated receptors in hemostasis, thrombosis and vascular biology," Journal of Thrombosis and Haemostasis, vol. 3, no. 8, pp. 1800-1814, 2005.

[26] A. C. Rosenkranz, K. Schrör, and B. H. Rauch, "Direct inhibitors of thrombin and factor $\mathrm{Xa}$ attenuate clot-induced mitogenesis and inflammatory gene expression in human vascular smooth muscle cells," Thrombosis and Haemostasis, vol. 106, no. 3, pp. 561-562, 2011.

[27] B. H. Rauch, E. Bretschneider, M. Braun, and K. Schrör, "Factor Xa releases matrix metalloproteinase-2 (MMP-2) from human vascular smooth muscle cells and stimulates the conversion of pro-MMP-2 to MMP-2: role of MMP-2 in factor Xa-induced DNA synthesis and matrix invasion," Circulation Research, vol. 90, no. 10, pp. 1122-1127, 2002.

[28] B. H. Rauch, E. Millette, R. D. Kenagy, G. Daum, and A. W. Clowes, "Thrombin- and factor Xa-induced DNA synthesis is mediated by transactivation of fibroblast growth factor receptor-1 in human vascular smooth muscle cells," Circulation Research, vol. 94, no. 3, pp. 340-345, 2004.

[29] G. Zhang, L. Yang, G. S. Kim et al., "Critical role of sphingosine1-phosphate receptor 2 (S1PR2) in acute vascular inflammation," Blood, vol. 122, no. 3, pp. 443-455, 2013.

[30] H. Obinata and T. Hla, "Sphingosine 1-phosphate in coagulation and inflammation," Seminars in Immunopathology, vol. 34, no. 1, pp. 73-91, 2012.

[31] H. Le Stunff, S. Milstien, and S. Spiegel, "Generation and metabolism of bioactive sphingosine-1-phosphate," Journal of Cellular Biochemistry, vol. 92, no. 5, pp. 882-899, 2004.

[32] L. A. Heffernan-Stroud and L. M. Obeid, "Sphingosine kinase 1 in cancer," Advances in Cancer Research, vol. 117, pp. 201-235, 2013.

[33] Y. Hisano, N. Kobayashi, A. Yamaguchi, and T. Nishi, "Mouse SPNS2 functions as a sphingosine-1-phosphate transporter in vascular endothelial cells," PLoS ONE, vol. 7, no. 6, Article ID e38941, 2012.

[34] S. Fukuhara, S. Simmons, S. Kawamura et al., "The sphingosine1-phosphate transporter Spns2 expressed on endothelial cells regulates lymphocyte trafficking in mice," The Journal of Clinical Investigation, vol. 122, no. 4, pp. 1416-1426, 2012. 
[35] K. Takabe, R. H. Kim, J. C. Allegood et al., "Estradiol induces export of sphingosine 1-phosphate from breast cancer cells via ABCC1 and ABCG2," Journal of Biological Chemistry, vol. 285, no. 14, pp. 10477-10486, 2010.

[36] P. Mitra, C. A. Oskeritzian, S. G. Payne, M. A. Beaven, S. Milstien, and S. Spiegel, "Role of ABCC1 in export of sphingosine-1phosphate from mast cells," Proceedings of the National Academy of Sciences of the United States of America, vol. 103, no. 44, pp. 16394-16399, 2006.

[37] J. Rivera, R. L. Proia, and A. Olivera, "The alliance of sphingosine-1-phosphate and its receptors in immunity," Nature Reviews Immunology, vol. 8, no. 10, pp. 753-763, 2008.

[38] M. MacEyka and S. Spiegel, "Sphingolipid metabolites in inflammatory disease," Nature, vol. 510, no. 7503, pp. 58-67, 2014.

[39] W. I. Leong and J. D. Saba, "S1P metabolism in cancer and other pathological conditions," Biochimie, vol. 92, no. 6, pp. 716-723, 2010.

[40] A. Olivera, M. L. Allende, and R. L. Proia, "Shaping the landscape: metabolic regulation of S1P gradients," Biochimica et Biophysica Acta: Molecular and Cell Biology of Lipids, vol. 1831, no. 1, pp. 193-202, 2013.

[41] K. Venkataraman, S. Thangada, J. Michaud et al., "Extracellular export of sphingosine kinase-la contributes to the vascular S1P gradient," Biochemical Journal, vol. 397, no. 3, pp. 461-471, 2006.

[42] H. Lee, E. J. Goetzl, and A. Songzhu, "Lysophosphatidic acid and sphingosine 1-phosphate stimulate endothelial cell wound healing," The American Journal of Physiology-Cell Physiology, vol. 278, no. 3, pp. C612-C618, 2000.

[43] Y.-G. Kwon, J.-K. Min, K.-M. Kim, D.-J. Lee, T. R. Billiar, and Y.-M. Kim, "Sphingosine 1-phosphate protects human umbilical vein endothelial cells from serum-deprived apoptosis by nitric oxide production," Journal of Biological Chemistry, vol. 276, no. 14, pp. 10627-10633, 2001.

[44] F. Wang, J. R. Van Brooklyn, J. P. Hobson et al., "Sphingosine 1-phosphate stimulates cell migration through a $G_{i}$-coupled cell surface receptor. Potential involvement in angiogenesis," Journal of Biological Chemistry, vol. 274, no. 50, pp. 3534335350, 1999.

[45] W. Zhang, J. An, H. Jawadi et al., "Sphingosine-1-phosphate receptor- 2 mediated $\mathrm{NF} \kappa \mathrm{B}$ activation contributes to tumor necrosis factor- $\alpha$ induced VCAM-1 and ICAM-1 expression in endothelial cells," Prostaglandins \& Other Lipid Mediators, vol. 106, pp. 62-71, 2013.

[46] Y. Shikata, K. G. Birukov, A. A. Birukova, A. Verin, and J. G. N. Garcia, "Involvement of site-specific FAK phosphorylation in sphingosine-1 phosphate- and thrombin-induced focal adhesion remodeling: role of Src and GIT,' The FASEB Journal, vol. 17, no. 15, pp. 2240-2249, 2003.

[47] W. Siess, "Athero- and thrombogenic actions of lysophosphatidic acid and sphingosine-1-phosphate," Biochimica et Biophysica Acta, vol. 1582, no. 1-3, pp. 204-215, 2002.

[48] B. J. McVerry and J. G. N. Garcia, "Endothelial cell barrier regulation by sphingosine 1-phosphate," Journal of Cellular Biochemistry, vol. 92, no. 6, pp. 1075-1085, 2004.

[49] C. Feistritzer and M. Riewald, "Endothelial barrier protection by activated protein $C$ through PAR1-dependent sphingosine 1phosphate receptor-1 crossactivation," Blood, vol. 105, no. 8, pp. 3178-3184, 2005.

[50] M. A. Hanson, C. B. Roth, E. Jo et al., "Crystal structure of a lipid G protein-coupled receptor," Science, vol. 335 , no. 6070, pp. 851855,2012
[51] M.-J. Lee, J. R. Van Brocklyn, S. Thangada et al., "Sphingosine-1phosphate as a ligand for the $G$ protein-coupled receptor EDG1," Science, vol. 279, no. 5356, pp. 1552-1555, 1998.

[52] C. H. Liu, S. Thangada, M.-J. Lee, J. R. Van Brooklyn, S. Spiegel, and T. Hla, "Ligand-induced trafficking of the sphingosine-1phosphate receptor EDG- 1," Molecular Biology of the Cell, vol. 10, no. 4, pp. 1179-1190, 1999.

[53] M. L. Allende, T. Yamashita, and R. L. Proia, "G-proteincoupled receptor $\mathrm{S}_{1} \mathrm{P}_{1}$ acts within endothelial cells to regulate vascular maturation," Blood, vol. 102, no. 10, pp. 3665-3667, 2003.

[54] J. Zhao, D. Garcia, A. Gartung, and M. Lee, "Sphingosine-1phosphate receptor subtype 2 signaling in endothelial senescence-associated functional impairments and inflammation," Current Atherosclerosis Reports, vol. 17, article 504, 2015.

[55] Q. Li, B. Chen, C. Zeng et al., "Differential activation of receptors and signal pathways upon stimulation by different doses of sphingosine-1-phosphate in endothelial cells," Experimental Physiology, vol. 100, no. 1, pp. 95-107, 2015.

[56] S. Chen, J. Yang, H. Xiang et al., "Role of sphingosine-1phosphate receptor 1 and sphingosine-1-phosphate receptor 2 in hyperglycemia-induced endothelial cell dysfunction," International Journal of Molecular Medicine, vol. 35, no. 4, pp. 11031108, 2015.

[57] J. G. N. Garcia, A. D. Verin, and K. L. Schaphorst, "Regulation of thrombin-mediated endothelial cell contraction and permeability," Seminars in Thrombosis and Hemostasis, vol. 22, no. 4, pp. 309-315, 1996.

[58] M. Popović, K. Smiljanić, B. Dobutović, T. Syrovets, T. Simmet, and E. R. Isenović, "Thrombin and vascular inflammation," Molecular and Cellular Biochemistry, vol. 359, no. 1-2, pp. 301313, 2012.

[59] Niessen F, C. Furlan-Freguia, J. A. Fernandez et al., "Endogenous EPCR/aPC-PAR1 signaling prevents inflammation-induced vascular leakage and lethality," Blood, vol. 113, no. 12, pp. 2859-2866, 2009.

[60] M. Tauseef, V. Kini, N. Knezevic et al., "Activation of sphingosine kinase-1 reverses the increase in lung vascular permeability through sphingosine-1-phosphate receptor signaling in endothelial cells," Circulation Research, vol. 103, no. 10, pp. 11641172,2008

[61] H. Takeya, E. C. Gabazza, S. Aoki, H. Ueno, and K. Suzuki, "Synergistic effect of sphingosine 1-phosphate on thrombininduced tissue factor expression in endothelial cells," Blood, vol. 102, no. 5, pp. 1693-1700, 2003.

[62] K. Chiba and K. Adachi, "Discovery of fingolimod, the sphingosine 1-phosphate receptor modulator and its application for the therapy of multiple sclerosis," Future Medicinal Chemistry, vol. 4, no. 6, pp. 771-781, 2012.

[63] F. Campos, T. Qin, J. Castillo et al., "Fingolimod reduces hemorrhagic transformation associated with delayed tissue plasminogen activator treatment in a mouse thromboembolic model," Stroke, vol. 44, no. 2, pp. 505-511, 2013.

[64] J. E. Hungerford and C. D. Little, "Developmental biology of the vascular smooth muscle cell: building a multilayered vessel wall," Journal of Vascular Research, vol. 36, no. 1, pp. 2-27, 1999.

[65] L. Badimon and G. Vilahur, "Thrombosis formation on atherosclerotic lesions and plaque rupture," Journal of Internal Medicine, vol. 276, no. 6, pp. 618-632, 2014.

[66] K.-I. Tamama, J. Kon, K. Sato et al., "Extracellular mechanism through the Edg family of receptors might be responsible for 
sphingosine-1-phosphate-induced regulation of DNA synthesis and migration of rat aortic smooth-muscle cells," Biochemical Journal, vol. 353, no. 1, pp. 139-146, 2001.

[67] A. J. Fegley, W. J. Tanski, E. Roztocil, and M. G. Davies, "Sphingosine-1-phosphate stimulates smooth muscle cell migration through galpha(i)- and pi3-kinase-dependent p38(MAPK) activation," Journal of Surgical Research, vol. 113, no. 1, pp. 32-41, 2003.

[68] W. J. Tanski, S. M. Nicholl, D. Kim, A. J. Fegley, E. Roztocil, and M. G. Davies, "Sphingosine-1-phosphate-induced smooth muscle cell migration involves the mammalian target of rapamycin," Journal of Vascular Surgery, vol. 41, no. 1, pp. 91-98, 2005.

[69] M. J. Kluk, C. Colmont, M.-T. Wu, and T. Hla, "Platelet-derived growth factor (PDGF)-induced chemotaxis does not require the $G$ protein-coupled receptor $\mathrm{S}_{1} \mathrm{P}_{1}$ in murine embryonic fibroblasts and vascular smooth muscle cells," FEBS Letters, vol. 533, no. $1-3$, pp. 25-28, 2003.

[70] M. J. Kluk and T. Hla, "Role of the sphingosine 1-phosphate receptor EDG-1 in vascular smooth muscle cell proliferation and migration," Circulation Research, vol. 89, no. 6, pp. 496-502, 2001.

[71] W. Tanski, E. Roztocil, and M. G. Davies, "Sphingosine-1phosphate induces $\mathrm{G}_{\alpha \mathrm{i}}$-coupled, PI3K/ras-dependent smooth muscle cell migration," Journal of Surgical Research, vol. 108, no. 1, pp. 98-106, 2002.

[72] A. Skoura and T. Hla, "Regulation of vascular physiology and pathology by the S1P2 receptor subtype," Cardiovascular Research, vol. 82, no. 2, pp. 221-228, 2009.

[73] A. Nodai, T. Machida, S. Izumi et al., "Sphingosine 1-phosphate induces cyclooxygenase- 2 via $\mathrm{Ca}^{2+}$-dependent, but MAPKindependent mechanism in rat vascular smooth muscle cells," Life Sciences, vol. 80, no. 19, pp. 1768-1776, 2007.

[74] Y. Liu, R. Wada, T. Yamashita et al., "Edg-1, the G proteincoupled receptor for sphingosine-1-phosphate, is essential for vascular maturation," Journal of Clinical Investigation, vol. 106, no. 8, pp. 951-961, 2000.

[75] K. Mizugishi, T. Yamashita, A. Olivera, G. F. Miller, S. Spiegel, and R. L. Proia, "Essential role for sphingosine kinases in neural and vascular development," Molecular and Cellular Biology, vol. 25, no. 24, pp. 11113-11121, 2005.

[76] M. Kono, Y. Mi, Y. Liu et al., "The sphingosine-1-phosphate receptors $\mathrm{S}_{1} \mathrm{P}_{1}, \mathrm{~S}_{2} \mathrm{P}_{2}$, and $\mathrm{S}_{3}$ function coordinately during embryonic angiogenesis," The Journal of Biological Chemistry, vol. 279, no. 28, pp. 29367-29373, 2004.

[77] A. Billich, N. Urtz, R. Reuschel, and T. Baumruker, "Sphingosine kinase 1 is essential for proteinase-activated receptor1 signalling in epithelial and endothelial cells," International Journal of Biochemistry and Cell Biology, vol. 41, no. 7, pp. 15471555, 2009.

[78] F. Niessen, F. Schaffner, C. Furlan-Freguia et al., "Dendritic cell PAR1-S1P3 signalling couples coagulation and inflammation," Nature, vol. 452, no. 7187, pp. 654-658, 2008.

[79] E. Bretschneider, M. Wittpoth, A.-A. Weber, E. Glusa, and K. Schrör, "Activation of $\mathrm{NF} \kappa \mathrm{B}$ is essential but not sufficient to stimulate mitogenesis of vascular smooth muscle cells," Biochemical and Biophysical Research Communications, vol. 235, no. 2, pp. 365-368, 1997.

[80] S. G. Mahajan, A. C. Fender, J. Meyer-Kirchrath et al., "A novel function of FoxO transcription factors in thrombin-stimulated vascular smooth muscle cell proliferation," Thrombosis and Haemostasis, vol. 108, no. 1, pp. 148-158, 2012.
[81] A. Böhm, A. Flößer, S. Ermler et al., "Factor-Xa-induced mitogenesis and migration require sphingosine kinase activity and S1P formation in human vascular smooth muscle cells," Cardiovascular Research, vol. 99, no. 3, pp. 505-513, 2013.

[82] S. Y. Xiang, S. S. Dusaban, and J. H. Brown, "Lysophospholipid receptor activation of RhoA and lipid signaling pathways," Biochimica et Biophysica Acta, vol. 1831, no. 1, pp. 213-222, 2013.

[83] J. I. Borissoff, S. Heeneman, E. Kilinç et al., "Early atherosclerosis exhibits an enhanced procoagulant state," Circulation, vol. 122 , no. 8, pp. 821-830, 2010.

[84] A. M. Whetzel, D. T. Bolick, S. Srinivasan et al., "Sphingosine-1 phosphate prevents monocyte/endothelial interactions in type 1 diabetic NOD mice through activation of the S1P1 receptor," Circulation Research, vol. 99, no. 7, pp. 731-739, 2006.

[85] Y. Yatomi, "Sphingosine 1-phosphate in vascular biology: possible therapeutic strategies to control vascular diseases," Current Pharmaceutical Design, vol. 12, no. 5, pp. 575-587, 2006.

[86] Y. Takuwa, Y. Okamoto, K. Yoshioka, and N. Takuwa, "Sphingosine-1-phosphate signaling and biological activities in the cardiovascular system," Biochimica et Biophysica Acta: Molecular and Cell Biology of Lipids, vol. 1781, no. 9, pp. 483488, 2008.

[87] L. Zhang, N. Urtz, F. Gaertner et al., "Sphingosine kinase 2 (SphK2) regulates platelet biogenesis by providing intracellular sphingosine 1-phosphate (S1P)," Blood, vol. 122, no. 5, pp. 791802, 2013.

[88] L. Zhang, M. Orban, M. Lorenz et al., "A novel role of sphingosine 1-phosphate receptor S1prl in mouse thrombopoiesis," Journal of Experimental Medicine, vol. 209, no. 12, pp. 2165-2181, 2012.

[89] T. Ulrych, A. Böhm, A. Polzin et al., "Release of sphingosine-1phosphate from human platelets is dependent on thromboxane formation," Journal of Thrombosis and Haemostasis, vol. 9, no. 4, pp. 790-798, 2011.

[90] Y. Yatomi, S. Yamamura, F. Ruan, and Y. Igarashi, "Sphingosine 1-phosphate induces platelet activation through an extracellular action and shares a platelet surface receptor with lysophosphatidic acid," The Journal of Biological Chemistry, vol. 272, no. 8, pp. 5291-5297, 1997.

[91] K. Venkataraman, Y.-M. Lee, J. Michaud et al., "Vascular endothelium as a contributor of plasma sphingosine 1phosphate," Circulation Research, vol. 102, no. 6, pp. 669-676, 2008.

[92] Y. Yatomi, T. Ohmori, G. Rile et al., "Sphingosine 1-phosphate as a major bioactive lysophospholipid that is released from platelets and interacts with endothelial cells," Blood, vol. 96, no. 10, pp. 3431-3438, 2000.

[93] D. English, Z. Welch, A. T. Kovala et al., "Sphingosine 1phosphate released from platelets during clotting accounts for the potent endothelial cell chemotactic activity of blood serum and provides a novel link between hemostasis and angiogenesis," The FASEB Journal, vol. 14, no. 14, pp. 2255-2265, 2000.

[94] M. Nagahashi, K. Takabe, K. P. Terracina et al., "Sphingosine-1phosphate transporters as targets for cancer therapy," BioMed Research International, vol. 2014, Article ID 651727, 7 pages, 2014.

[95] R. H. Kim, K. Takabe, S. Milstien, and S. Spiegel, "Export and functions of sphingosine-1-phosphate," Biochimica et Biophysica Acta-Molecular and Cell Biology of Lipids, vol. 1791, no. 7, pp. 692-696, 2009. 
[96] J. Niessen, G. Jedlitschky, M. Grube et al., "Expression of ABCtype transport proteins in human platelets," Pharmacogenetics and Genomics, vol. 20, no. 6, pp. 396-400, 2010.

[97] G. Jedlitschky, K. Tirschmann, L. E. Lubenow et al., "The nucleotide transporter MRP4 (ABCC4) is highly expressed in human platelets and present in dense granules, indicating a role in mediator storage," Blood, vol. 104, no. 12, pp. 3603-3610, 2004.

[98] G. Jedlitschky, A. Greinacher, and H. K. Kroemer, "Transporters in human platelets: physiologic function and impact for pharmacotherapy," Blood, vol. 119, no. 15, pp. 3394-3402, 2012.

[99] M. Knorr, T. Münzel, and P. Wenzel, "Interplay of NK cells and monocytes in vascular inflammation and myocardial infarction," Frontiers in Physiology, vol. 5, article 295, 2014.

[100] R. Bar-Shavit, A. Kahn, J. W. Fenton II, and G. D. Wilner, "Chemotactic response of monocytes to thrombin," Journal of Cell Biology, vol. 96, no. 1, pp. 282-285, 1983.

[101] R. Colognato, J. R. Slupsky, M. Jendrach, L. Burysek, T. Syrovets, and T. Simmet, "Differential expression and regulation of protease-activated receptors in human peripheral monocytes and monocyte-derived antigen-presenting cells," Blood, vol. 102, no. 7, pp. 2645-2652, 2003.

[102] C. López-Pedrera, M. Á. Aguirre, P. Buendía et al., "Differential expression of protease-activated receptors in monocytes from patients with primary antiphospholipid syndrome," Arthritis and Rheumatism, vol. 62, no. 3, pp. 869-877, 2010.

[103] T. Li, H. Wang, and S. He, "Induction of interleukin-6 release from monocytes by serine proteinases and its potential mechanisms," Scandinavian Journal of Immunology, vol. 64, no. 1, pp. 10-16, 2006.

[104] V. A. Shatrov, V. Lehmann, and S. Chouaib, "Sphingosine-1phosphate mobilizes intracellular calcium and activates transcription factor NF- $\kappa$ B in U937 cells," Biochemical and Biophysical Research Communications, vol. 234, no. 1, pp. 121-124, 1997.

[105] M. Fueller, D. A. Wang, G. Tigyi, and W. Siess, "Activation of human monocytic cells by lysophosphatidic acid and sphingosine-1-phosphate," Cellular Signalling, vol. 15, no. 4, pp. 367-375, 2003.

[106] C. Q. Duong, S. M. Bared, A. Abu-Khader, C. Buechler, A. Schmitz, and G. Schmitz, "Expression of the lysophospholipid receptor family and investigation of lysophospholipid-mediated responses in human macrophages," Biochimica et Biophysica Acta, vol. 1682, no. 1-3, pp. 112-119, 2004.

[107] D. R. Gude, S. E. Alvarez, S. W. Paugh et al., "Apoptosis induces expression of sphingosine kinase 1 to release sphingosine-1phosphate as a 'come-and-get-me' signal," The FASEB Journal, vol. 22 , no. 8, pp. 2629-2638, 2008.

[108] C. Nussbaum, S. Bannenberg, P. Keul et al., "Sphingosine-1phosphate receptor 3 promotes leukocyte rolling by mobilizing endothelial P-selectin," Nature Communications, vol. 6, article 6416, 2015.

[109] S. Mahajan-Thakur, B. D. Sostmann, A. C. Fender et al., "Sphingosine-1-phosphate induces thrombin receptor PAR-4 expression to enhance cell migration and COX-2 formation in human monocytes," Journal of Leukocyte Biology, vol. 96, no. 4, pp. 611-618, 2014.

[110] M. Knapp, A. Lisowska, P. Zabielski, W. Musiał, and M. Baranowski, "Sustained decrease in plasma sphingosine-1phosphate concentration and its accumulation in blood cells in acute myocardial infarction," Prostaglandins \& Other Lipid Mediators, vol. 106, pp. 53-61, 2013.

[111] A. Polzin, T. Rassaf, A. Böhm et al., "Aspirin inhibits release of platelet-derived sphingosine-1-phosphate in acute myocardial infarction," International Journal of Cardiology, vol. 170, no. 2, pp. e23-e24, 2013. 


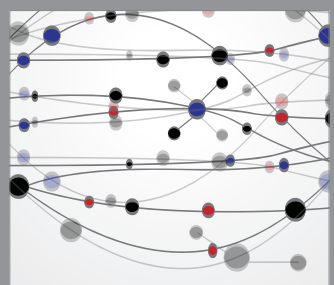

The Scientific World Journal
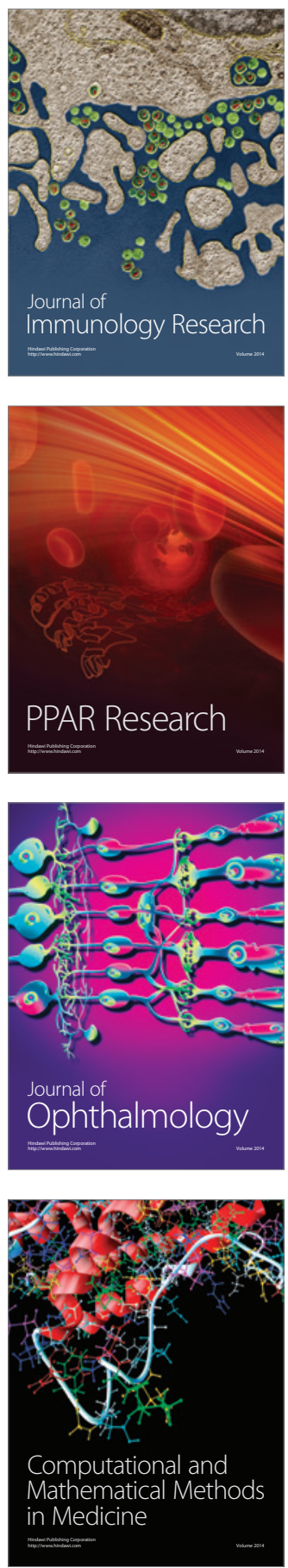

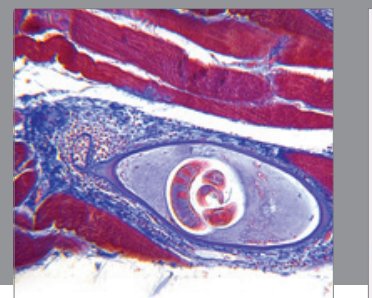

Gastroenterology

Research and Practice
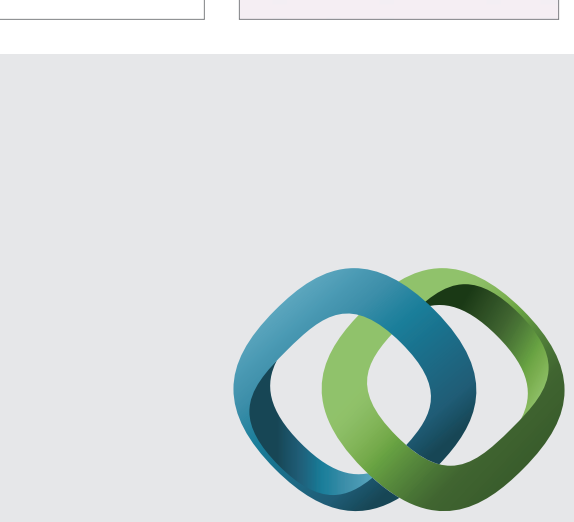

\section{Hindawi}

Submit your manuscripts at

http://www.hindawi.com
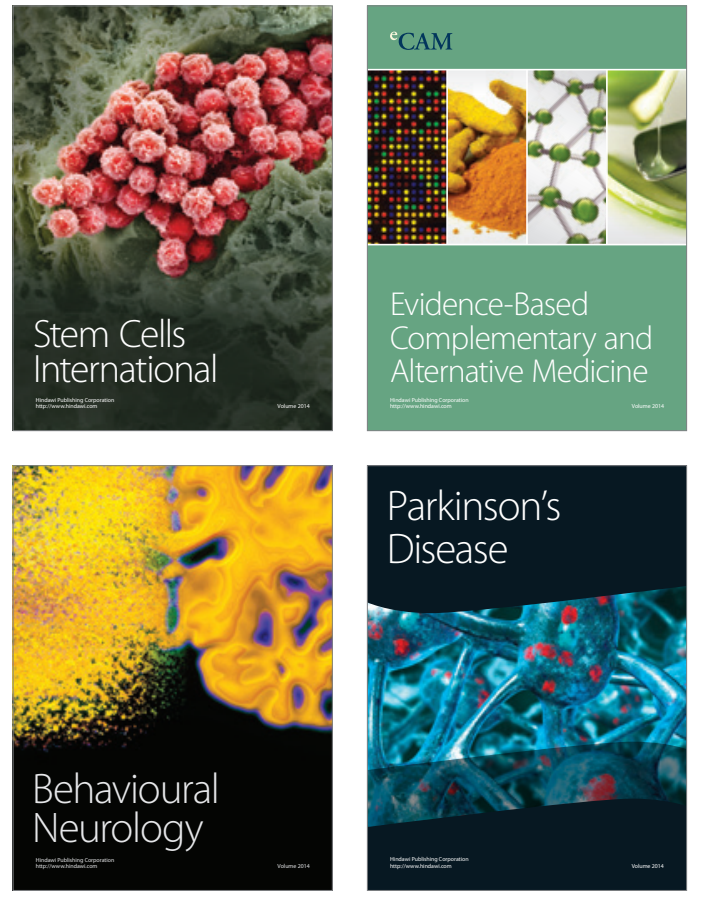
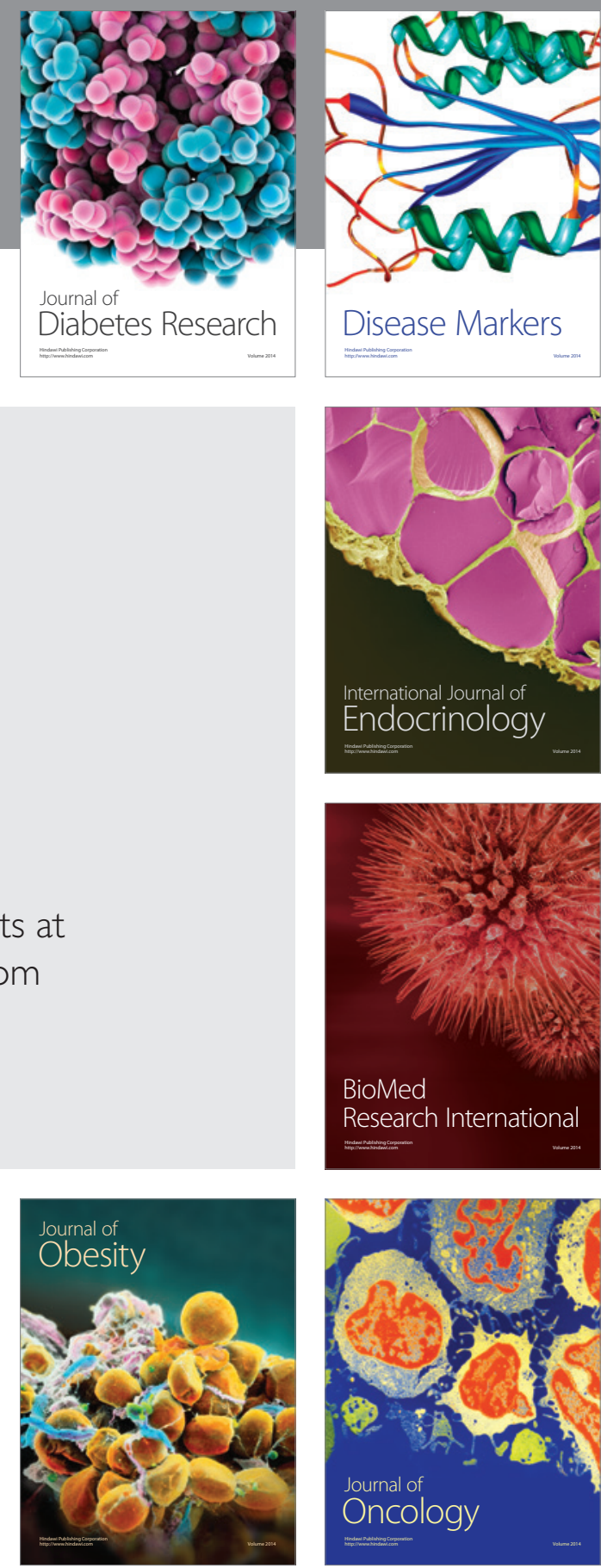

Disease Markers
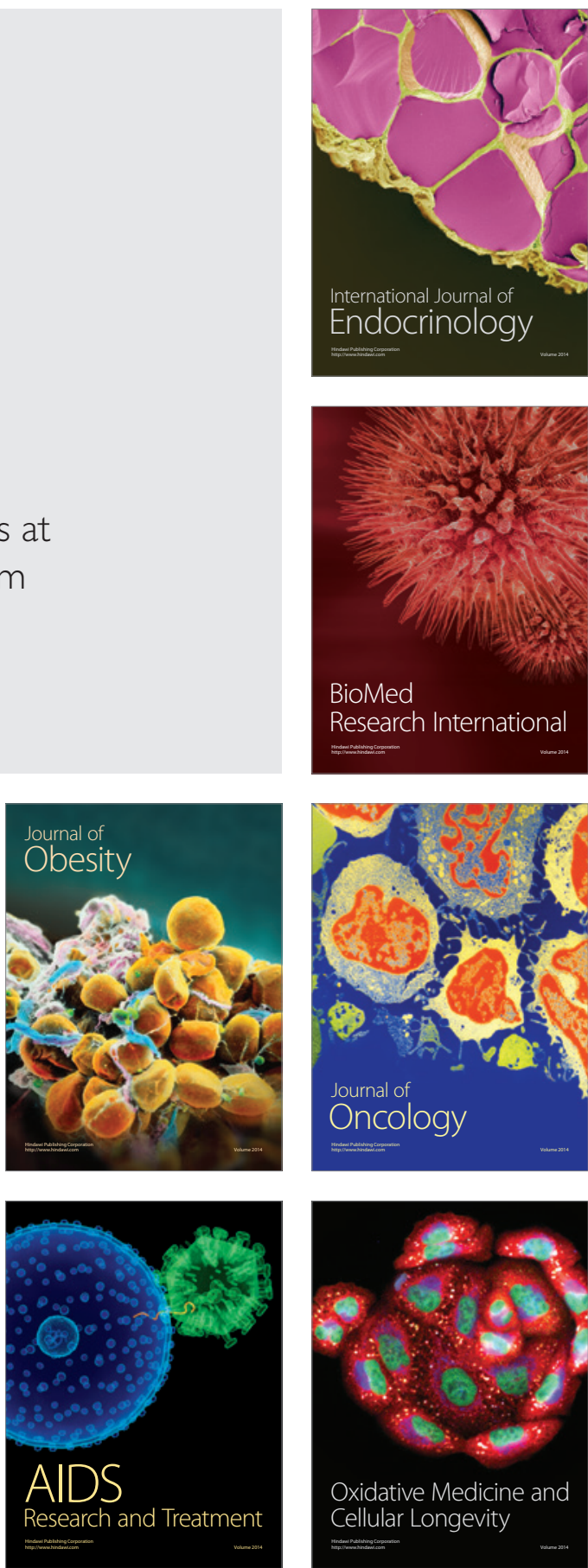